Artigo recebido em 07/04/2015

Aprovado em 19/08/2015

Rafael Rangel Winch Universidade Federal de

Santa Maria (UFSM) rangelrafael16@hotmail. com

Mestrando do Programa de Pós-Graduação em Comunicação da UFSM. Jornalista formado pela UFSM.

Viviane Borelli Universidade Federal de Santa Maria (UFSM) viviborelli10@gmail.com

Docente do Programa de Pós-Graduação em Comunicação da UFSM. Doutora em Ciências da Comunicação pela Unisinos.

\section{Sentidos sobre o jornalismo investigativo no discurso de reportagens da Agência Pública}

\author{
Rafael Rangel Winch e Viviane Borelli
}

\begin{abstract}
Resumo
Nesta pesquisa, objetivamos identificar sentidos referentes à prática do jornalismo investigativo por meio da análise de marcas discursivas em reportagens de Pública - Agência de Jornalismo Investigativo e Reportagem. Para tanto, utilizamos o aporte teórico-metodológico da Análise do Discurso (AD) para analisar quatro reportagens a partir de três categorias analíticas: Processo de apuração; Contraponto dos fatos; Relato humanizado. Através da análise, verificamos que a prática investigativa da Pública é marcada pela busca por diferentes versões dos fatos; pelo cruzamento de dados para contrapor informações; pela utilização de documentos como fonte e estratégia de apuração e pela humanização das narrativas para a contextualização das matérias.
\end{abstract}

\section{Palavras-chave}

Jornalismo investigativo, Discurso, Agência Pública.

\begin{abstract}
In this research, we have the purpose of identify senses related to investigative journalism practice through analyses of discursive marks in reports of Pública Investigative Journalism Agency and Report. For this, we use theoretical methodological contribution from Discourses Analysis (DA). We analyze four reports from three analytic categories: Counting Process; Counterpoint of Facts; Humanized Description. Through the analysis, we verify that the Pública's investigative practice is marked for search for different versions from facts; the data crossing to oppose information; the documents utilization like sources and poll strategy and the humanization of narratives to contextualize matters.
\end{abstract}

\section{Keywords}

Investigative journalism; Discourse; Pública Agency. 


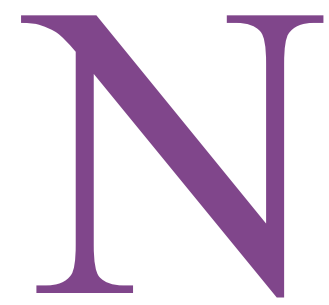

o jornalismo contemporâneo, preceitos como o interesse público são negligenciados em detrimen-

to de aspectos econômicos, políticos e ideológicos. Constrangidas pela receita dos anúncios, as notícias cada vez mais explicitam o seu caráter mercantil, dificultando o debate público de questões socialmente relevantes. Em busca de sustentação e ampliação do seu negócio, as empresas jornalísticas parecem se esquecer do papel social do ofício, bem como de sua importância para a cidadania e democracia.

Contudo, para além da cobertura instantânea e programada do jornalismo, observamos que o ambiente digital propicia o surgimento de iniciativas jornalísticas que se nomeiam como "independentes" e que se propõem a produzir conteúdos através de novos modelos de produção e de financiamento. Esses projetos, que se espalham por vários países, buscam se ancorar na prática do jornalismo investigativo para abordar temáticas sociais ignoradas ou superficialmente reportadas pelo jornalismo convencional.

No Brasil, desde 2011, Pública - Agência de Reportagem e Jornalismo Investi-

${ }^{1} O$ artigo é um recorte do Trabalho de Conclusão de Curso intitulado " $O$ jornalismo investigativo no discurso de reportagens $d a$ Agência Pública", que foi defendido em 09 de dezembro de 2014, como requisito para obtenção do grau de Bacharel em Comunicação Social - Jornalismo pela Universidade Federal de Santa Maria. gativo produz matérias sobre temáticas sociais. A organização é financiada por entidades do Terceiro Setor e defende a democratização do acesso à informação no país. Pública faz parte da rede internacional, mas sobretudo latino-americana, Global Investigative Network, que conta com outros projetos semelhantes: o ILD Reporteros do Peru; a La Silla Vacía da Colômbia; o Plaza Publica da Guatemala; o Confidencial da Nicarágua; o El Faro de El Salvador, o Animal Político do
México e o Plan V do Equador. O ProPublica e o Center for Investigative Reporting, organizações dos Estados Unidos, também inspiraram a inciativa brasileira. Além disso, a Agência é a parceira oficial da Wikileaks no país.

Através do exercício do jornalismo investigativo - aspecto que a nomeia -, Pública dedica-se a produzir grandes reportagens. Neste artigo ${ }^{1}$, buscamos refletir sobre os elementos que constituem a prática desse tipo de jornalismo. Sendo assim, o principal objetivo é identificar sentidos referentes ao jornalismo investigativo a partir do mapeamento de marcas discursivas em reportagens de Pública. Pretendemos também, como objetivos específicos, compreender como esses sentidos são construídos e apontar as singularidades discursivas das matérias.

A partir de Verón $(2004$, p. 61) compreendemos que o discurso pode designar qualquer conjunto significante, ou seja, é um "lugar de investimento de sentido". Assim, o que é produzido, o que circula e o que produz efeitos dentro de uma sociedade serão sempre discursos. Para o autor, é necessário identificar e descrever as classes dos discursos, bem como sua economia de funcionamento.

De acordo com a perspectiva discursiva, o texto se constitui em um processo de interação, definido pragmaticamente enquanto unidade complexa de significação, sem desconsiderar as condições de sua produção (ORLANDI, 2006). Dessa forma, a AD se interessa por "descrever, explicar e avaliar criticamente os processos de produção, circulação e consumo dos sentidos" (PINTO, 2002, p. 11) relacionados a determinado discurso na sociedade.

Do ponto de vista metodológico, aten- 
tamos ao fato de que a $\mathrm{AD}$ "examina as manifestações textuais submetidas às mensagens em situação de produção e recepção" (FAUSTO NETO, 2014, p. 39). Ao compreendermos que é através dos textos que se realiza o trabalho de leitura e de análise, buscamos identificar marcas discursivas em reportagens de Pública que produzam sentidos referentes a características do jornalismo investigativo.

No que se refere ao procedimento de seleção do corpus, fez-se inicialmente uma pré-leitura das matérias publicadas por Pública, entre os anos de 2011 e 2014 . A partir desse mapeamento, identificamos quatro eixos temáticos: Ditadura Militar, Copa do Mundo de Futebol, Amazônia e Direitos Humanos. Dentro desses quatro grandes temas há subtemas, tais como: meio ambiente, cidadania, sistema penitenciário, moradias, tráfico de drogas, movimentos sociais, aborto, indústria de armas, saúde pública e violência policial.

Além desse mapeamento, utilizamos como critério a seleção de matérias produzidas por jornalistas que fazem parte da equipe de Pública. Dessa forma, as reportagens realizadas em parceria com outras organizações e também as financiadas por meio de concursos de micro-bolsas ${ }^{2}$ foram desconsideradas. Também levamos em conta a produção das matérias por repórteres distintos. Para tentar abarcar a diversidade dos conteúdos produzidos essencialmente pela Agência, optamos por selecionar uma reportagem de cada ano (2011, 2012, 2013 e 2014) e que estivessem inseridas em temáticas distintas. Desse modo, as reportagens selecionadas para a análise são: Forçados a Matar; O dinheiro sumiu da escola, e a educação também; Depois que o trator passou; e Maternidade condenada.
A reportagem Forçados a Matar (R1) aborda o envolvimento de camponeses em mortes no conflito do Araguaia, durante o período da Ditadura Militar Brasileira. Por sua vez, O dinheiro sumiu da escola; e a educação também (R2) discute os desvios de recursos na educação em escolas do estado do Pará, entre outros problemas relacionados à infraestrutura educacional da região. Depois que o trator passou (R3) trata da situação precária dos moradores das comunidades do Comando e do Buraco, zona sul de São Paulo, que tiveram suas casas destruídas pelas obras do monotrilho, relacionado à Copa do Mundo de Futebol. Por fim, Maternidade Condenada (R4) aborda a situação de mães encarceradas, que têm seus direitos violados em presídios do estado de São Paulo.

Discutimos inicialmente algumas das principais características da prática jornalística investigativa para depois procedermos à análise das quatro matérias com o objetivo de identificar marcas discursivas que produzam sentidos referentes ao jornalismo investigativo.

\section{O jornalismo investigativo}

Historicamente, a investigação ocupa um lugar especial entre as principais características da atividade jornalística. A própria mídia noticiosa sempre referenciou tal preceito como um aspecto inerente à construção dos seus conteúdos. Entretanto, nem todo jornalismo produzido atualmente é, de fato, investigativo (SEQUEIRA, 2005). Uma considerável parte das notícias chega praticamente pronta às redações, por meio do formato de press-releases, oriunda de assessorias de imprensa, de secretarias de comunicação de órgãos públicos, privados e de Orga-
${ }^{2}$ Além de sua própria produção de conteúdos, Pública reproduz reportagens de outros veículos, grupos e coletivos de comunicação do Brasil e traduz produções internacionais. A organização também veicula matérias dos vencedores de seus concursos, produzidas por jornalistas independentes, que não compõem sua equipe. 
nizações Não-Governamentais (ONGs). A partir dessa lógica, a profissão tende a ser exercida sem nenhuma investigação.

Apesar de sua reconhecida história, do uso recorrente do termo pelos próprios jornalistas e da existência de entidades consolidadas, como a Associação Brasileira de Jornalismo Investigativo (Abraji), o jornalismo investigativo, enquanto uma categoria jornalística específica, ainda não é consenso geral entre teóricos do campo e profissionais da área no Brasil. A resistência em atribuir tal diferenciação sustenta-se no pensamento de que toda prática jornalística deveria pressupor investigação e ser inerente ao ofício.

Entretanto, como alerta Fortes (2005, p. 8), para que possamos compreender “a extensão dessa novidade é preciso libertar-se da concepção simplista, embora essencialmente verdadeira, de que todo jornalismo é investigativo. Essa não é uma verdade absoluta, nem mesmo para casos carimbados com a marca". O autor ressalta que algumas das reportagens que se intitulam fruto de jornalismo investigativo, como flagrantes de corrupção e escândalos na área política, "não passaram nem perto de uma investigação" (FORTES, 2005, p. 8).

Os estudos sobre o jornalismo investigativo costumam apresentar a modalidade como uma radicalização dos principais valores do jornalismo. Assim, a busca pela verdade e a problematização dos fatos são enquadradas como preceitos rigorosamente cultuados e seguidos para alcançar o sucesso de uma investigação. Porém, cabe ressaltar que pesquisadores e profissionais da área também enxergam a categoria a partir de especificidades em relação ao jornalismo convencional. Conforme Fortes (2005), o jornalismo in- vestigativo pressupõe um contexto mais complexo, em que a superação do caráter noticioso implicará na necessidade de mais tempo para apuração dos fatos.

Sequeira (2005) também considera o tempo um fator primordial para a efetivação do jornalismo investigativo, visto que através de uma lógica de produção diferenciada, "as reportagens investigativas estão na contramão do fluxo de informação, quer pela apuração entre as fontes utilizadas, quer pelo tempo de que o repórter necessita para concluir seu trabalho" (SEQUEIRA, 2005, p. 38).

Desse modo, percebe-se que a prática desse tipo de jornalismo ultrapassa o simples objetivo de reportar os fatos, já que há um considerável desapego ao imediatismo. Compartilhando dessa perspectiva, Lopes (2003, p. 14) explica que "o jornalismo de investigação tem objetivos concretos que transcendem a informação diária, cuja produção fica velha em 24 horas". Ainda conforme o autor, desvendar atos ilícitos, divulgar o que os poderes públicos querem esconder, mostrar como funcionam esses órgãos e informar os eleitores sobre o desempenho dos políticos são alguns aspectos frequentemente associados às investigações jornalísticas (LOPES, 2003). A própria história demarcou ao jornalismo investigativo um círculo de relações e conflitos políticos, por vezes, perigosos.

Todavia, é preciso ressaltar que a prática investigativa extrapola as questões referentes ao mundo da política, pois como afirma Dines (1986), a modalidade não se limita às sensações e aos escândalos. $\mathrm{O}$ autor considera que o jornalismo investigativo está relacionado ao jornalismo interpretativo ou analítico, já que, ao inquirir sobre as causas e origens dos fatos, 
ainda busca a ligação entre eles, ao mesmo tempo em que oferece a explicação da sua ocorrência. Essa prática específica também supera o mero denuncismo, na medida em que "pode comportar uma atitude grave, estudiosa e, sobretudo, responsável" (DINES, 1986, p. 95).

Conforme Santoro (2004), três características básicas definem a prática do jornalismo investigativo: a elaboração da investigação deve ser essencialmente do jornalista, e não de outras áreas, como a justiça e a polícia e interessados particulares; a investigação se realiza através da superação de tentativas de impedimentos e obstáculos por parte de algum poder interessado em ocultar as informações; os temas interessam à opinião pública e deixam de lado a vida privada das pessoas. A visão do autor é uma das mais referendadas nos estudos sobre o jornalismo investigativo, que costumam discutir a categoria com enfoque predominante na práxis da profissão.

Entretanto, em sua pesquisa, Lima (2011) vai além das classificações essencialmente ligadas à ordem técnica. $\mathrm{O}$ autor classifica o jornalismo investigativo como gênero jornalístico considerando alguns aspectos fundamentais: a pauta $\mathrm{e}$ os saberes de reconhecimento, a apuração e seus processos de procedimento e a narração, com o texto e edição. Dessa forma, a definição não se limita às estratégias de apuração utilizadas pelos repórteres, uma vez que situa o jornalismo investigativo como um processo de começo, meio e fim. A partir disso, pode-se admitir que a singularidade desse tipo de jornalismo ainda concretiza-se pelo seu próprio conteúdo final, visto que "a investigação jornalística produz um tipo de conhecimento diferenciado, tanto pela técnica de apuração verticalizada, quanto pelo labor da pesquisa empírica" (LIMA, 2011, p. 172).

Para o estudo, é pertinente a compreensão de que o jornalismo investigativo independe de editoria/área para ser exercido. As temáticas podem ser as mais variadas possíveis. Entretanto, o enfoque dos conteúdos costuma privilegiar questões sociais e de interesse público. Nesse sentido, Lage (2005, p. 139) compreende a modalidade como "um esforço para evidenciar misérias presentes ou passadas da sociedade, injustiças cometidas; contar como as coisas são ou foram ou como deveriam ser ou ter sido". Assim, muitas problemáticas sociais, constantemente negligenciadas pela mídia noticiosa, podem sair do ostracismo através de produções investigativas.

De acordo com Waisbord (2000), é através da reportagem que a modalidade investigativa pode ser plenamente exercida. Na mesma perspectiva, Lopes (2003) e Lage (2005) classificam o jornalismo investigativo, respectivamente, como "reportagem em profundidade" e "forma extremada de reportagem". A visão dos autores se justifica pelo fato de que a maioria das investigações jornalísticas costuma se ancorar neste gênero do jornalismo. Por necessitar ser essencialmente verossímil (SODRÉ; FERRARI, 1986), trazer mais fontes e problematizar as informações, o gênero caracteriza-se como uma extensão e aprofundamento do formato-notícia.

Após refletirmos sobre alguns aspectos relativos ao jornalismo investigativo, analisamos as matérias. Para evidenciarmos marcas discursivas que produzem sentidos referentes à prática do jornalismo investigativo, definimos três catego- 
rias de análise: Processo de apuração; Contraponto dos fatos; Relato humanizado. Elas foram estabelecidas com base no referencial teórico-metodológico e a partir da pré-leitura das reportagens de Pública.

Antes de partirmos para a análise, no entanto, ressaltamos que não buscamos identificar sentidos sobre um determinado tema (consumo, meio ambiente, moda, por exemplo) via discursos. O objetivo consiste em evidenciar marcas discursivas que produzam sentidos que remetem à prática do jornalismo investigativo. $\mathrm{Ou}$ seja, a problemática de pesquisa assinala uma distinção em relação aos trabalhos que utilizam a $\mathrm{AD}$ como dispositivo analítico para evidenciar tendências e singularidades de coberturas jornalísticas sobre temas específicos. Como lembra Verón (2004, p. 70), “o analista dos discursos, por definição, sempre é colocado em posição de reconhecimento", em que sua leitura é mediada pelos métodos aplicados às superfícies discursivas.

Dito isso, procede-se à análise das reportagens em que foram eleitos trechos, nomeados como Sequências Discursivas (SDs) e que estão relacionadas a cada uma das categorias analíticas. As reportagens que constituem o corpus são indicadas pelas siglas R1, R2, R3 e R4; e as SDs, pelas siglas SD1, SD2 e assim sucessivamente. Na transcrição das SDs, as marcas discursivas referidas na análise são grifadas em itálico.

\section{Processo de apuração}

Através dessa categoria analítica analisamos marcas discursivas que se referem ao processo de apuração das reportagens de Pública, destacando, sobretudo, o percurso e os métodos de apuração dos repórteres. Cabe ressaltarmos a visão de Sequeira (2005), ao considerar que as técnicas e as estratégias empreendidas na apuração jornalística diferenciam o jornalismo convencional do investigativo.

Observamos que a Agência se preocupa em referenciar alguns elementos que auxiliaram no desenvolvimento das matérias, bem como evidenciar o contato dos jornalistas com os ambientes da apuração e com as fontes. A partir disso, destacamos algumas estratégias que Pública emprega para sustentar a veracidade de suas reportagens e o rigor do seu processo de apuração.

Em Forçados a Matar (R1), evidenciamos marcas discursivas relacionadas aos elementos que serviram de base para a sua produção. Tal reportagem é constituída, majoritariamente, por informações oriundas de documentos. Nesse caso, a documentação utilizada ainda cumpre o papel de fonte, característica comum no jornalismo investigativo (FORTES, 2005).

(SD1) Os contornos dessa história vêm de dezenas de depoimentos anexados ao processo 82.0024682-5, aberto em fevereiro de 1982, na 1a Vara da Justiça Federal, por iniciativa dos familiares de 25 guerrilheiros desaparecidos. (R1)

(SD2) Além de esclarecer as circunstâncias da prisão e morte de diversos guerrilheiros, os depoimentos mostram que a tortura praticada contra os "terroristas" foi adaptada para destruir o caráter e a dignidade dos que se viram apanhados pelo conflito sem 
condições de resistir. (R1)

As SDs 1 e 2 não apenas explicitam o uso de documentos na matéria, mas também denotam sentidos que dizem respeito à forma como se desenvolveu o processo de apuração. Além disso, tais referências à documentação possibilitam que o leitor tenha acesso à procedência dos dados apresentados na reportagem. Desse modo, percebemos um movimento de legitimação do discurso de Pública, que visa tornar-se o mais verídico possível através do esclarecimento da origem das informações.

As constantes menções aos documentos ao longo da R1 colaboram para a construção dos sentidos referentes à veracidade das informações e ao rigor na apuração. A reportagem repete, explica e enfatiza onde apurou as informações para embasar sua narrativa. Podemos interpretar isso como uma estratégia discursiva, na medida em que reforça o efeito de verdade da matéria. Quando Pública reitera que determinada informação consta em tal documento não está apenas evidenciando a sua fonte, visto que, ao mesmo tempo, o enunciado aciona a percepção do leitor para o elemento mais significativo da apuração dessa reportagem: a pesquisa documental.

Em O dinheiro sumiu da escola, e a educação também (R2), mapeamos SDs em que é possível observar uma dimensão mais explícita do processo de investigação da Agência. Nessas SDs, o discurso evidencia o percurso de apuração e destaca o empenho de Pública em coletar e relacionar informações para o desenvolvimento da matéria.

(SD3) Pública foi ao Pará em busca dos investimentos desti- nados à educação. Encontrou salas em ruínas, alunos sem livro, caderno, merenda e até sem aula. (R2)

(SD4) Antes de chegar a essa conclusão, a Pública coletou informações sobre a qualidade da educação no norte do país e fez um detalhado cruzamento dos dados sobre os desvios na verba que deveria ser investida nas escolas do Pará. (R2)

Há aspectos em comum no discurso desses trechos, sobretudo a referência da Agência a si mesma. Tal estratégia reforça a identidade de Pública como uma organização atuante e compromissada com os preceitos básicos do jornalismo investigativo, que realiza um trabalho de produção rigoroso e incansável. Esse movimento discursivo de autorreferenciação é evidenciado em "Pública foi ao Pará" (SD3), e "Pública coletou informações" (SD4). Situar Pública no local onde os fatos acontecem significa reforçar os sentidos de "fomos até lá" e de "presenciamos a realidade como ela é". A partir disso, o discurso suscita aspectos do imaginário sobre o papel do jornalismo, como por exemplo: ir a campo, investigar pessoalmente os fatos, ouvir várias pessoas. $\mathrm{O}$ trecho "fez um detalhado cruzamento dos dados" (SD4) vai ao encontro das considerações de Santoro (2004), que destaca essa ação como um aspecto fundamental nos processos de apuração do jornalismo investigativo.

\section{Contraponto dos fatos}

Identificamos sentidos relacionados ao Contraponto dos fatos em distintos 
níveis. Este aspecto, característico da reportagem investigativa, foi empregado como uma estratégia discursiva que pode estabelecer discursos de oposição, refutação e comparação em relação à realidade dos fatos. O contraponto foi utilizado por Pública para apontar contradições no (e a partir do) discurso das fontes.

O uso de conjunções como o "mas" e o "porém" produz sentidos referentes ao contraponto realizado pelas reportagens. A partir desse recurso, as narrativas se articulam com base em informações que contrariam determinadas declarações e situações. Contrapor fatos e versões faz parte da prática do jornalismo investigativo e foi identificado com intensidade na $\mathrm{SD}$, da reportagem Depois que o trator passou (R3):

(SD5) A CDHU informou que 488 famílias foram removidas e que, dessas, 429 já teriam sido atendidas. Mas os números não batem com os do Metrô: segundo o órgão, apenas 383 famílias receberam atendimento. As duas entidades estaduais também divergem quanto ao número de pessoas que permanecem vivendo entre os escombros. Para o Metrô são 10 famílias, enquanto para a CDHU, são 48 famílias, que ocupam 37 edificações. (R3)

Pública contrapõe as informações da Companhia de Desenvolvimento Habitacional e Urbano (CDHU) com os dados apresentados pelo Metrô paulista. O texto destaca a existência de divergências e levanta dúvidas sobre qual das entidades estaria falando a verdade. Assim, consideramos que os sentidos de contraponto identificados em SD5 vão ao encontro do objetivo da prática investigativa, que é buscar a mais completa versão da verdade (BURGH, 2008), ouvindo os vários lados de cada caso abordado e explicitando possíveis contradições.

$\mathrm{Na}$ R3, assim como em outras matérias analisadas, os depoimentos das fontes foram fundamentais para a construção da narrativa. No jornalismo investigativo, fugir das fontes mais óbvias é outro preceito básico (LOPES, 2003). A seguir, destacamos a sequência discursiva que faz parte da reportagem Maternidade Condenada (R4).

(SD6) São Paulo tem oito unidades prisionais teoricamente preparadas para que as presas exerçam o direito à maternidade e as crianças o de ficar junto da mãe, principalmente nos primeiros anos de vida. Um direito violado mesmo no período de amamentação apesar das orientações do Ministério da Saúde sobre a importância do leite materno até dois ou três anos de idade, como enfatiza o defensor público Bruno Shimizu, do Núcleo Especializado de Situação Carcerária. (R4)

Em "teoricamente preparadas" da SD6, o discurso da reportagem visa reforçar a ideia de falha e de inoperância das unidades prisionais. Assim, os sentidos do contraponto da Agência são reiterados ao longo do enunciado, principalmente, em "um direito violado" e "apesar das orientações do Ministério da Saúde". O trecho se sustenta a partir da declaração de um defensor público do Núcleo Es- 
pecializado de Situação Carcerária. Por meio desse tipo de depoimento de fontes, a matéria busca apontar as irregularidades do sistema penitenciário paulista no que se refere aos direitos das mães presidiárias. A R4 ainda traz relatos de presidiárias, que reforçam a desumanidade do tratamento com as mães carcerárias. Por trazer depoimentos apoiados na memória, as fontes testemunhais possuem grande valor para a reportagem investigativa (SEQUEIRA, 2005).

\section{Relato humanizado}

Por meio dessa categoria analítica, identificamos sentidos relacionados à humanização das narrativas. Todavia, é essencial ressaltar a nossa compreensão sobre duas questões: 1) o relato de cenas, gestos e comportamento dos personagens são aspectos constitutivos do discurso das reportagens de Pública 2) a definição do jornalismo investigativo não se limita a características como o processo de apuração das matérias (LIMA, 2011), observado na categoria anterior. Entendemos ainda que, a partir do Relato humanizado, posteriormente, pode-se extrair o que há de universal nos fatos. Ou seja, torna-se possível ampliar o relato para além de uma situação particular (PEREIRA JUNIOR, 2010).

A R1, como já explicamos, aborda um conflito ocorrido no período do regime militar brasileiro. Por tratar de fatos situados no passado, Pública aciona uma memória discursiva pertencente a outro tempo histórico, ancorada no relato do cotidiano dos camponeses. Em SD7 e SD8, identificamos sentidos relacionados à humanização do relato da matéria, construídos, sobretudo, a partir da descrição de cenas e personagens.
(SD7) Pescavam nos igarapés do Araguaia e sabiam se orientar na floresta, seguir o rastro de um veado ou caititu abatido com tiro de espingarda e carneado ainda quente, com as facas afiadas, para facilitar o transporte da caça até a casa, onde seria assado na brasa ou cozido lentamente no leite de castanha. (R1)

(SD8) Curavam com ervas e rezas as crises de malária, e gostaram quando os rapazes e moças chegaram da cidade grande trazendo remédios e conhecimento para socorrer um parto difícil, curar uma ferida, aliviar dores. Os "paulistas", quase todos jovens, compravam da farinha e do mel, e pareciam à vontade em suas casas, fumando e palestrando até a lua ir alta no céu. (R1)

As SDs 7 e 8 localizam-se no início da R1 e cumprem a função de contextualizar o tema. Os trechos, em certa medida, se assemelham à linguagem de um jornalismo mais literário. Por meio da descrição detalhada do comportamento de pessoas que viveram naquele período, o discurso realça a imaginação sobre os fatos. Dessa forma, o relato humanizado possui uma dimensão significativa na narrativa, visto que desempenha o papel de situar o leitor diante das informações que posteriormente serão problematizadas. O próprio emprego de verbos no pretérito imperfeito - "pescavam", “curavam", “compravam" e "pareciam" - compõe a reiteração de sentidos relacionados à outra época, essencial para a compreensão da reportagem. Através desses enunciados, percebemos ainda que, ao destacar ações de sujeitos situados nesse período históri- 
co, a reportagem busca evidenciar alguns testemunhos dos fatos, considerando que o narrador precisa "parecer presente (mesmo que não esteja)" (SODRÉ; FERRARI, 1986, p. 91).

Os trechos abaixo foram extraídos do início da R4:

(SD9) Clarice* abre a porta de casa com o filho no colo, um menino bonito e falante de dois anos de idade, que mostra a roupa nova, o cachorro, se agarra no pescoço dela e diz "ó, essa é minha mãe". Lá dentro, a avó ajuda a dar conta dos outros dois filhos, uma menina de 15 e um menino de 13 , que chegam da escola. (R4)

(SD10) Quando a entrevista começa a avó tira as crianças da sala e o sorriso desaparece do rosto de Clarice. "Eu tive dois filhos dentro do sistema penitenciário. O primeiro algemada pelos pés e pelas mãos", diz. (R4)

Com as SDs 09 e 10, observamos que a reportagem constrói sentidos sobre a entrevistada, enfatizando ações $-\neg$ "Clarice abre a porta" - e reações - "o sorriso desaparece do rosto de Clarice". Assim, Pública busca humanizar os personagens da narrativa para posteriormente abordar questões mais centrais, que nesse caso são os direitos violados das mães encarceradas. Como destacam Sodré e Ferrari (1986, p. 67), “a reportagem destina-se basicamente a chamar atenção do leitor e conquistá-lo para a leitura do texto". Verificamos que, através das aberturas de suas matérias, a Agência adota um relato mais humanizado.

Nas reportagens analisadas, Pública busca humanizar suas narrativas por meio de três estratégias elencadas por Sodré e Ferrari (1986). São elas: o realce da visão (detalhes dos ambientes de apuração), o realce da imaginação (descrição das ações de personagens de uma época passada em R1) e o realce da pessoa (enfoque em testemunhos dos fatos). Desse modo, evidenciamos uma tentativa de fuga da convencional abertura informativa do lide clássico, adotando um estilo mais literário.

\section{Considerações finais}

Objetivamos analisar marcas discursivas em reportagens de Pública que evidenciassem características do jornalismo investigativo. Através do mapeamento de tais marcas, buscamos identificar sentidos referentes a diferentes aspectos dessa prática jornalística. Por meio da análise, foi possível perceber como esses sentidos são construídos e como eles remetem a distintas facetas da prática investigativa.

Por meio da categoria Contraponto dos fatos, observamos como as reportagens apontaram contradições, irregularidades e falhas. A construção de sentidos relacionados ao contraponto acontece, sobretudo, por meio dos depoimentos das fontes, muitas vezes contraditórios. Notamos que Pública assumiu, na maioria das reportagens, uma postura investigativa que questiona e critica os fatos. A partir da leitura das SDs enquadradas nesta categoria, percebemos, em diferentes níveis, a mobilização de sentidos que visam denunciar questões de interesse público.

Os sentidos referentes ao Processo de apuração foram construídos a partir da exposição da trajetória e das estratégias 
de investigação das reportagens. Algumas matérias de Pública evidenciaram a documentação como método de apuração, que resguarda sentidos de memória, registro e veracidade. Através de contínuas referências ao próprio trabalho de apuração, o percurso das investigações foi destacado pelo discurso da organização. Desse modo, as reportagens explicitaram que estiveram nos locais onde os fatos aconteceram e enfatizaram o contato direto com os entrevistados.

Em Relato humanizado, verificamos como Pública construiu sentidos sobre os cenários e personagens de investigações. Na abertura das matérias, há uma narrativa mais dramatizada que explora os detalhes dos ambientes. Na sequência, as reportagens contextualizaram e aprofundaram suas narrativas por meio do destaque à figura humana. Para tanto, focalizaram "pessoas comuns", que raramente ganham espaço no jornalismo convencional e, em seguida, exploraram os aspectos mais universais das pautas.

A perspectiva da análise discursiva foi essencial para a compreensão do jornalismo investigativo como algo que ultrapassa o empirismo do processo de apuração. Por isso, buscamos analisar como esse processo e outras características dessa prática podem ser evidenciadas através do discurso das reportagens. Com isso, tentamos ir além de uma visão meramente descritiva a respeito desse tipo de prática jornalística, que costuma enquadrá-lo, sobretudo, a partir de aspectos de ordem técnica.

Novamente, torna-se importante recorrermos ao postulado de Lima (2011), que pensa o jornalismo investigativo como um processo de começo, meio e fim. A partir deste olhar, assumimos também o jornalismo como uma ação discursiva, buscando mapear, em distintas dimensões, características que denotassem a prática de um jornalismo investigativo por parte de Pública. Esse movimento analítico foi desafiante, visto que nossa problemática de pesquisa apresenta diferenças em relação a outros trabalhos que empregam a AD como aporte teórico-metodológico para a leitura de coberturas temáticas, por exemplo.

A maioria dos trabalhos científicos que abordam o jornalismo investigativo como objeto ou tema são estudos de casos. Alguns livros que trazem o termo "investigativo" em seus títulos o analisam do ponto de vista da ética que circunda o ofício, bem como problematizam as estratégias de uso de câmeras escondidas e infiltrações. Reconhecemos que tais métodos, por vezes, são característicos desse tipo de jornalismo. Contudo, a proposta foi lançar um olhar mais amplo, que também abarcasse questões relativas à construção das narrativas das reportagens, como o próprio relato humanizado.

Compreendemos a importância da mídia noticiosa, que diariamente lida com a produção dos acontecimentos, através da lógica do deadline. Entretanto, percebemos que devido a uma série de valores e constrangimentos da prática diária, nem sempre alguns dos princípios básicos do jornalismo são cumpridos, tais como privilegiar o interesse público e ouvir diferentes pontos de vista.

Por seu turno, o jornalismo investigativo pode contemplar questões relegadas pelo jornalismo convencional. A partir da busca por fatos ocultados da sociedade, o jornalismo investigativo consegue revelar histórias que até então estavam silenciadas. Evidentemente, a superação 
da cobertura imediatista requer paciência visto que uma reportagem investigativa e também investimento (FORTES, 2005), não nasce da noite para o dia.

\section{Referências bibliográficas}

BURGH, Hugo de (Org.). Jornalismo investigativo. São Paulo: Roca, 2008.

DINES, Alberto. O papel do jornal. São Paulo: Summus, 1986.

FAUSTO NETO, Antonio. A Análise do Discurso. In: CITELLI, Adilson et al (orgs.). Dicionário de comunicação: escolas, teorias e autores. São Paulo: Contexto, 2014.

FORTES, Leandro. Jornalismo Investigativo. São Paulo: Contexto, 2005.

LAGE, Nilson. A reportagem: teoria e técnica de entrevista e pesquisa jornalística. Rio de Janeiro: Record, 2005.

LIMA, Samuel. Insuficiências teóricas e desafios. In: CHRISTOFOLETTI, Rogério; KARAM, Francisco José (org). Jornalismo Investigativo e Pesquisa Científica.. Florianópolis: Insular, 2011.

LOPES, Dirceu Fernandes. Caminhos do Jornalismo Investigativo. In: LOPES, Dirceu Fernandes; PROENÇA, José Luiz (org). Jornalismo Investigativo. SP: Publisher, 2003.

ORLANDI, Eni Puccinelli. Análise de discurso: princípios e procedimentos. Campinas: Pontes, 2006.

PEREIRA JUNIOR, Luiz Costa. A apuração da notícia. Petrópolis, Rio de Janeiro: Vozes, 2010.

PINTO, Milton José. Comunicação e discurso. $2^{\text {a }}$ ed. São Paulo: Hacker Editores, 2002.

SANTORO, Daniel. Técnicas de Investigación. México: Nuevo Periodismo, 2004.

SEQUEIRA, Cleofe. Jornalismo investigativo: o fato por trás da notícia. São Paulo: Summus, 2005. 
SODRÉ, Muniz e FERRARI, Maria Helena. Técnica de reportagem: notas sobre a narrativa jornalística. São Paulo: Summus, 1986.

VERÓN, Eliseo. Fragmentos de um tecido. São Leopoldo: Unisinos, 2004.

WAISBORD, Silvio. Watchdog journalism in South America: news, accountability and democracy. Nova York: Columbia University Press, 2000.

Estudos em Jornalismo e Mídia está sob a licença Creative Commons 2.5 